1 Send proof to:

2 Ruedi Nager

3 Institute of Biodiversity, Animal Health and Comparative Medicine

4 Graham Kerr Building

5 University of Glasgow

6 Glasgow G12 8QQ

7 Phone: ++44 1413305976

8 Email: Ruedi.Nager@glasgow.ac.uk

9

10

12

17

18

19

20

21

22

23

\title{
Changing Numbers of Three Gull Species in the British Isles
}

RUEDI G. NAGER ${ }^{1, *}$ AND NINA J. O’HANLON ${ }^{2}$

${ }^{1}$ Institute of Biodiversity, Animal Health and Comparative Medicine, Graham Kerr Building University of Glasgow, Glasgow, G12 8QQ, Scotland, U.K.

${ }^{2}$ Institute of Biodiversity, Animal Health and Comparative Medicine, The Scottish Centre for Ecology and the Natural Environment, University of Glasgow, Rowardennan, Drymen, Glasgow, G63 0AW, Scotland, U.K. 
Abstract.-Between-population variation of changes in numbers can provide insights into factors influencing variation in demography and how population size or density is regulated. Here, we describe spatio-temporal patterns of population change of Herring Gull (Larus argentatus), Lesser Black-backed Gull (L. fuscus) and Great Black-backed Gull (L. marinus) in the British Isles from national censuses and survey data. The aim of this study was to test for density-dependence and spatial variation in population trends as two possible, but not mutually exclusive, explanations of population changes with important implications for the understanding of these changes. Between 1969 and 2013 the three species showed different population trends with Herring Gulls showing a strong decline, Great Black-backed Gulls a less pronounced decline and Lesser Black-backed Gulls an increase until 2000 but then a decline since. Population changes also varied between different regions of the British Isles, with the Atlantic coast showing declines and the North Sea coast increases in all three species. Population changes were density-dependent in the Herring Gull, and Lesser Blackbacked Gulls showed faster population increases at lower Herring Gull densities. Contrasting numbers of gulls nest in coastal habitats or on roofs (mainly in urban habitats). Herring Gulls seem to seek refuge in urban environments, whereas Lesser Black-backed Gulls expand their range into the urban environment. The large declines in hitherto abundant species create a dilemma for conservation bodies in prioritizing conservation policies. The spatial variation in population changes and the differences between species suggest that there is no single cause for the observed changes, thus requiring region-specific conservation management strategies. Received ?????????, accepted ???????? 
Key words.—density-dependence, Great Black-backed Gull, Herring Gull, Larus

48 argentatus, Larus fuscus, Larus marinus, Lesser Black-backed Gull, population trends,

49 productivity, roof-nesting.

50

51 Running Head: TRENDS IN LARGE BRITISH GULLS 
Most species show between-population variation in demography, but case studies covering a substantial part of a species' range are rare (but see Dhondt 2001). Exploration of spatial variation in demography over a large range may provide insights into factors influencing variation in demography and how population size or density is regulated because throughout a larger range the populations are likely to be exposed to a larger range of environmental conditions increasing the power of the study (Bairlein 2003). Here, we want to explore the spatial variation in population trends of the three large gull species, Herring Gull (Larus argentatus), Lesser Black-backed Gull (L. fuscus) and Great Black-backed Gull (L. marinus) breeding in the British Isles, northeastern Atlantic.

The British Isles host more seabirds than comparable areas at similar latitudes in continental Europe because they are surrounded by highly productive seas. Some of the seabird species have shown large fluctuations in numbers over the last century. Because of their colonial nesting behavior, which allows collection of large numbers of birds and eggs, seabirds were particularly vulnerable to human exploitation that peaked in the 19th century in the British Isles (Newton 2013). After protective legislation was put in place to curb human exploitation, and an upsurge in food supplies mainly resulting from human fishing activities, many seabird populations increased again and spread in the latter half of the 20th century (Cramp et al. 1974; Lloyd et al. 1991; Mitchell et al. 2004). Three of the seabirds that showed such large fluctuations were the large Larus species: Great Black-backed Gull, Herring Gull, and Lesser Black-backed Gull. The British Isles host a significant proportion of their biogeographic population (from 16\% in L. marinus to 63\% for L. fuscus; Mitchell et al. 2004). Insofar as we know, the three large Larus species were not uncommon in the British Isles during the 19th century, with their main distribution being to the north of Scotland and on the western seaboards of Scotland, Wales and Ireland (Holloway 1996). During most of the 20th century, following the implementation of protective legislation in the early 1900s, 
their populations expanded and colonized new areas and/or reoccupied areas from which they had been driven by persecution (Cramp et al. 1974). For example, the Herring Gull is considered to have increased annually by 13\% from the 1930s to the 1970s (Chabrzyk and Coulson 1976). Reasons for this increase are thought to be increased protection and increased food availability, mainly from human sources, refuse and fisheries discards (Furness and Monaghan 1997; but see Coulson this volume). Most recently, however, worrying declines for all three species were recorded (Eaton et al. 2013).

The population dynamics of marine top predators, like the Larus species, may reflect environmentally induced changes in resource availability (Davoren and Montevecchi 2003), or they may be self-regulated through local prey depletion (Birt et al. 1987). Changes in a top predator's environment may cascade through bottom-up control (i.e., from prey to predator). If spatio-temporal variation in resource availability is mainly determined by environmental effects, colonies exploiting the same local resources would be expected to show similar population trends and, therefore, geographic clusters would show similar dynamics (regional variation hypothesis). On the other hand, demographic parameters of top predators may be negatively correlated with their density, possibly through local prey depletion or reduced resource availability through interference (Furness and Birkhead 1984; Lewis et al. 2001; Ainley et al. 2003), so that there is a top-down control (i.e., from predator to prey). These two mechanisms have profoundly different implications for population control, and determining which of these mechanisms is most important is critical for our understanding of the population dynamics of Larus species (Montevecchi 1993).

The aim of this study was to test for spatial variation and density-dependence in population change in the three large Larus species in the British Isles between 1969 and 2013 to gain insights into two possible, but not mutually exclusive explanations for the observed population changes. By including different species that differ in their general ecology (only 
the Lesser Black-backed Gull is migratory; all three species differ in their use of food supplies (Furness et al. 1992; Noordhuis and Spaans 1992; Kim and Monaghan 2006)), variation in population changes among species and among regions may point toward potential causes of changes in population abundance in the British Isles.

\section{METHODS}

We used two sources of data to evaluate the changes in abundance of the large gulls in Great Britain, Isle of Man, Channel Islands and Ireland, hereafter referred to as the British Isles. First, comprehensive counts of seabirds nesting in the British Isles were carried out in 1969-1970 (Operation Seafarer; Cramp et al. 1974), in 1985-1988 (Seabird Colony Register; Lloyd et al. 1991) and 1998-2002 (Seabird 2000; Mitchell et al. 2004). And secondly, we used more recent surveys from the Seabird Monitoring Programme (SMP; Joint Nature Conservation Committee 2014a) that give an index to estimate the trends in gull populations since Seabird 2000.

Operation Seafarer, Seabird Colony Register and Seabird 2000 all followed the same essential methodologies to quantify numbers of coastal nesting gulls. Essentially, the entire coastline within $5 \mathrm{~km}$ of the high-water line (on Orkney, Shetland and Western Isles all colonies were considered coastal even if more than $5 \mathrm{~km}$ from the coastline) where there were previous reports on seabird presence were surveyed and all apparently occupied nests (AON, well-constructed nest either containing eggs or young or capable of holding eggs, a well-constructed nest attended by an adult, or an adult apparently incubating) were counted during the daytime in the peak incubation period when most gulls were expected to be on eggs (Mitchell et al. 2004). Coastlines in remote and sparsely populated areas (e.g., north and northwest Scotland, western and southern Ireland) were incompletely surveyed in Operation Seafarer and Seabird Colony Register; therefore, total abundance might have been slightly 
underestimated in the 1970s and 1980s. Seabird 2000 ensured that the coverage of those regions was much improved and where some gaps remained, notably western and southern Ireland, only few gulls had been previously recorded from that area (Hannon et al. 1997). Therefore, abundances of coastal breeding large gulls are comparable across 1969-2002. Seabird 2000 also covered roof-nesting gulls (colonies on man-made structures, mostly roofs) and gulls nesting at inland sites. Additional specialist national surveys of roof-nesting gulls were also carried out in 1974-1976 (Monaghan and Coulson 1977) and in 1994-1995 (Raven and Coulson 1997) allowing us to separate population changes between different breeding habitats (coastal nesting vs. roof-nesting pairs). AON counts were provided per administrative areas which correspond to the English and Welsh counties, Scottish and Northern Ireland districts and Irish vice-counties.

To look at changes in population abundance of gulls since Seabird 2000, we included information of the SMP surveys. Started in 1986, SMP monitors an extensive sample of colonies each year, supplemented with more intensive monitoring of demographic parameters at key colonies. It covers 26 seabird species that regularly breed in the British Isles. For gulls, annual count data from an extensive sample of gull colonies are compiled and values for missing years (where these existed) were estimated using an 'imputation' method (Thomas 1993). The estimates of population abundance from the SMP is an index expressed as a percentage of the first year in the time series (1986) that was set as $100 \%$. Note that SMP data only cover the U.K., whereas Operation Seafarer, Seabird Colony Register and Seabird 2000 cover the British Isles. However, by the mid-1980s the numbers of gulls breeding in the Republic of Ireland were so small (typically $<10 \%$ of the count of the whole of the British Isles) that the differences between U.K. and British Isles numbers were negligible. Based on the absolute number of gulls in Seabird Colony Register (1985-1988), when the SMP population index was set at $100 \%$, and the SMP population index for 2000 , we can calculate 
the number of gulls estimated by the SMP survey and compare this to the more exhaustive total count by Seabird 2000 to assess how representative is the SMP population index. We then used the SMP population index for 2013 (Joint Nature Conservation Committee 2014a) to estimate the total number of gulls in 2013 and investigate population trends in the three larger gulls since 2002. The SMP also records data on productivity and we extracted annual productivity rates for Herring, Lesser Black-back and Great Black-backed gulls in order to test for temporal changes in productivity between 1986 and 2012 (the period for which data are available).

Within the database, seabird population estimates can be determined over two scales; the individual colony and the administration area, with the exception of the administration areas around Glasgow where population estimates were combined and categorized as the Clyde. Changes in abundance are expressed in two ways. To compare changes between intervals of different duration we calculated percentage change per annum (\% pa) as $\sqrt[t]{\mathrm{N}(\mathrm{t}) / \mathrm{N}(0)}$ where $\mathrm{N}(0)$ is the initial count and $\mathrm{N}(\mathrm{t})$ is the count $\mathrm{t}$ years later. Secondly, we calculated population growth rate (GR) from the late 1960s to 2000 using the following formula based on Guillaumet et al. (2014):

$$
\mathrm{GR}=\left(\mathrm{N}_{\mathrm{t}+1}-\mathrm{N}_{\mathrm{t}}\right) / \text { Maximum }\left[\mathrm{N}_{\mathrm{t}+1}, \mathrm{~N}_{\mathrm{t}}\right]
$$

where $\mathrm{N}_{\mathrm{t}+1}$ and $\mathrm{N}_{\mathrm{t}}$ are two counts and Maximum $\left[\mathrm{N}_{\mathrm{t}+1}, \mathrm{~N}_{\mathrm{t}}\right]$ is either the earlier or later count, whichever was the higher value. GR were calculated per administrative area instead of individual colony to buffer against short-distance movements between neighboring colonies. The equation based on Guillaumet et al. (2014) was used instead of the more conventional calculation for population growth as it deals better with administrative areas with gull populations (e.g., Lancashire, West Sussex, Hampshire, Suffolk, East Sussex, Dorset) newly established during the study period, whilst still providing a good estimate of the population change (Guillaumet et al. 2014). Our estimate of GR is monotonically related to the 
conventional measure of population growth $\left(\mathrm{N}_{\mathrm{t}+1} / \mathrm{N}_{\mathrm{t}}\right)$ with Spearman correlation coefficient $\mathrm{r}_{\mathrm{s}}$ $=1.0$ in all three species. GR thus provides provides an adequate alternative to describing population trends where new populations are established during the study period but as it requires both $\mathrm{N}_{\mathrm{t}}$ and $\mathrm{N}_{\mathrm{t}+1}$, it does not provide a tool for predicting future abundance (Guillaumet et al. 2014).

We then clustered administrative areas into distinct biogeographic zones, each having a specific oceanography (primarily temperature, depth and current) that supports characteristic biological communities (Dinter 2001). Coastal waters around the British Isles are included in two regions of the northeastern Atlantic by the OSPAR Commission (2014): Greater North Sea east of $5^{\circ} \mathrm{W}$ and Celtic Sea west of $5^{\circ} \mathrm{W}$. For U.K. waters only, the Joint Nature Conservation Committee identified Regional Seas Regions (RSR; Joint Nature Conservation Committee 2014b) on a finer scale based on the same biogeographic principles as the OSPAR Commission regions. For the purpose of our analyses, we used the following RSRs (maintain the same numbers as Joint Nature Conservation Committee 2014b; Fig. 2): 1. Northern North Sea between Duncansby Head and Flamborough; 2. Southern North Sea between Flamborough and Dover Straits; 3. Eastern English Channel between Dover Straits and the line between Weymouth to Cherbourg; 4. Western English Channel \& Celtic Sea west of the line between Weymouth to Cherbourg and bounded in the northeast by the Celtic Sea front; 6. Irish Sea bounded in the south by the Celtic Sea front and in the north by the line from the Mull of Kintyre to Fair Head; 7. Minches \& West Scotland bounded in the south by the line from the Mull of Kintyre to Fair Head and in the north by the line from the Butt of Lewis to Cape Wrath; and 8. Scottish Continental Shelf north of the line from the Butt of Lewis to Cape Wrath and west of Duncansby Head. The Joint Nature Conservation Committee's RSRs do not include waters of the Republic of Ireland, and although the Western English Channel \& Celtic Sea appears to extend around Ireland, initial analyses 
showed that some trends in Irish gull colonies differed from those in the rest of the Western English Channel \& Celtic Sea (analyses not shown). We therefore included Irish vicecounties not bordering the Celtic Sea (north-west of Cork) in a separate RSR (referred as 4a), and vice-counties bordering the Celtic Sea were included in RSR 4. Because for each RSR we had multiple measures of GR (one for each administrative area) we could calculate a mean GR and 95\% confidence interval of the mean per RSR. If the 95\% confidence interval does not overlap with 0 than we can say that the population in that RSR increased (positive GR) or declined (negative GR). For population trend between 2000 and 2013 based on the SMP Index we have only one value at the start and end for that period and we cannot judge whether observed changes in numbers are statistically significant or not.

To test for spatial variation in population trends, we compared GRs between RSRs using ANOVAs with administrative area GRs as response variable and RSR as a fixed factor, carried out separately for each of the three species. For the effects of density on GRs, we analyzed the data separately for the periods of Operation Seafarer to Seabird Colony Register and Seabird Colony Register to Seabird 2000, and related GRs to the absolute abundance at the beginning of each interval (Operation Seafarer and Seabird Colony Register, respectively). To account for regional variation in both population size and GR, we analyzed for the effect of population size on GR using a general linear model with RSR as a fixed effect. To investigate the relationship between numbers of pairs in different breeding habitats we analyzed a relationship between number of roof-nesting pairs in Seabird 2000 against change in number of coastal-nesting pairs between 1969 and 2002 across all species using a general linear model including species as a factor. This analysis only included Herring and Lesser Black-backed gulls as insufficient numbers for the Great Black-backed Gull were available. Because changes in annual productivity can cause changes in population size we explored temporal changes in annual productivity rates of each species using correlations. All 
statistical analyses were carried out using SPSS (IBM Corp. 2013). A significance level of $P$ $=0.05$ was used, and results are presented as means $\pm 95 \%$ confidence intervals of means.

\section{RESULTS}

There have been changes in numbers of breeding pairs of Herring, Great Blackbacked and Lesser Black-backed Gulls in the British Isles between 1969 and 2002, but theydiffer between the three species (Fig. 1). Operation Seafarer (1969-1970) recorded 343,600 AON of coastal nesting Herring Gulls (Cramp et al. 1974). By the mid-1980s, the number of coastal-nesting Herring Gulls declined to nearly half that number (177,000 AON; Lloyd et al. 1991; 1.1\% decline per annum) and by Seabird 2000, it decreased further to 147,100 AON; Mitchell et al. 2004; 1.4\% decline per annum). Overall the Herring Gull population of the British Isles showed a negative average GR of -0.27 with a $95 \%$ confidence interval (-0.43 to $-0.11, n=72$ administrative areas) that did not overlap with 0 . Coastalnesting Great Black-backed Gulls were less numerous than Herring Gulls and showed a less pronounced decline in numbers: Operation Seafarer = 22,200 AON (Cramp et al. 1974); Seabird Colony Register = 20,900 AON (Lloyd et al. 1991; 0.4\% decline per annum); and Seabird $2000=$ 19,700 AON (Mitchell et al. 2004; 0.5\% decline per annum since Seabird Colony Register). The average GR of Great Black-backed gulls was 0.055 with a 95\% confidence interval (-0.12 to $0.23, n=58$ administrative areas) which overlapped with 0 . Coastal-nesting Lesser Black-backed Gulls showed an increase in numbers by 29\% (1.5\% per annum) from Operation Seafarer (50,000 AON; Cramp et al. 1974) to Seabird Colony Register (64,400 AON; Lloyd et al. 1991) and by 42\% (2.7\% per annum) from Seabird Colony Register to Seabird 2000 (91,300 AON; Mitchell et al. 2004). The average GR of coastal-nesting Lesser Black-backed Gulls of the British Isles was 0.37 with a 95\% confidence interval ( 0.21 to $0.53, n=64$ administrative areas) that did not overlap with 0 . 
Between Operation Seafarer and Seabird 2000, the GR of Herring Gulls differed between RSRs (ANOVA: $F_{7,63}=2.78, P=0.014$; Table 1; Fig. 2a). Numbers of coastalnesting Herring Gulls decreased in the northern and western parts of the British Isles but did not show clear trends elsewhere (Table 1; Fig. 2a). Coastal-nesting Great Black-backed Gulls showed population increases in the Northern North Sea and the Eastern English Channel, but no clear trends elsewhere with the differences in GR between RSRs marginally significant (ANOVA: $F_{6,47}=2.28, P=0.050$; Table 1; Fig. 2c). Although the GR of coastalnesting Lesser Black-backed Gulls did not differ significantly between RSRs (ANOVA: $F_{7,56}$ $=1.96, P=0.076)$, Lesser Black-backed Gull numbers increased in RSRs in the southern part of the British Isles, but declined Minches and West Scotland and no clear trends in the other regional seas (Table 1; Fig 2b).

We found density-dependent GR for coastal-nesting Herring Gulls during both sampling intervals (Operation Seafarer to Seabird Colony Registry and Seabird Colony Registry to Seabird 2000) with administrative areas that held the largest numbers of Herring Gulls showed the greatest per capita declines in local abundance (Table 2). There was no evidence of negative correlations between GR and population abundance in the other two species (Table 2). We also found weak evidence for an interaction between Lesser Blackbacked and Herring gulls; local Lesser Black-backed Gull populations increased the least in administrative areas with the highest numbers of Herring Gulls in the period between Seabird Colony Registry and Seabird 2000, but all other species interactions were not significant (Table 2).

Data on roof-nesting gulls suggested few birds were nesting on man-made structures in the 1970s (Fig. 1). In the 1980s and 1990s, the number of roof-nesting gulls increased dramatically in Herring and Lesser Black-backed gulls (Fig. 1). The relationship between number of roof-nesting pairs in Seabird 2000 and changes in numbers of coastal-nesting pairs 
per RSR differed significantly between Herring and Lesser Black-backed gulls (interaction species by absolute change in coastal-breeding numbers: GLM: $F_{1,14}=10.43, P=0.006$; Fig. 3). In Herring Gulls, RSR that lost the largest number in coastal-nesting pairs were also the areas with the largest number of roof-nesting gulls in Seabird 2000 (correlation: $r=-0.75, n=$ 8 RSR, $P=0.019)$. In contrast, for the Lesser Black-backed Gull the RSRs with the largest increases in coastal-nesting pairs also held the highest numbers of roof-nesting pairs in 2000 ( $r=0.82, n=8, P=0.007)$. However, the number of roof-nesting pairs in Herring and Lesser Black-backed gulls are smaller than the changes in population abundance in the coastal areas (Fig. 3).

To assess the trends in gull numbers since 2000, we used the SMP index . Because the SMP covers only a sample of colonies, we first compared the projections of the SMP index from 1986-2000 with the more extensive data from Seabird 2000. The agreement between the trend in gull numbers between the estimate from the SMP index and Seabird 2000 was very good for all three species (Fig. 1). Between 2000 and 2013, the numbers of Herring Gulls further declined (30\% decline between 2000 and 2013 or 3.0\% per annum) as did the numbers of Great Black-backed Gulls (24\% decline between 2000 and 2013 or 3.0\% per annum). Since 2000, the number of Lesser Black-backed Gulls also started to decline (48\% decline between 2000 and 2013 or 5.0\% per annum).

Annual productivity rates declined between 1986 and 2012 for Herring Gulls (correlation: $r=-0.44, n=23$ years, $P=0.036)$ and Great Black-backed Gulls $(r=-0.66, n=$ 22 years, $P<0.001)$ but did not change over time in Lesser Black-backed Gulls $(r=0.18, n$ $=23$ years, $P=0.411$ ). 
We found considerable variation in changes in population trends between species, and

within species variation between regions and habitats in the three Larus species Herring, Lesser Black-backed, and Great Black-backed gulls in the British Isles. The variation in GR between species and regions suggests that there is no one overall cause of the changes in abundance in Herring, Lesser Black-backed, and Great Black-backed gulls for the whole of the British Isles.

The changes in numbers of coastal-nesting pairs of Herring, Great Black-backed and Lesser Black-backed gulls between 1969 and 2013 differed between the three species. Herring Gulls exhibited a steep and significantly negative growth rate (GR), Great Blackbacked Gulls showed a small and non-significant change whereas over that same period the population of the Lesser Black-backed Gull significantly increased. The numbers of Herring and Great Black-backed gulls possibly peaked in the 1960s and 1970s following a period of increased protection and food availability, while the Lesser Black-backed Gull continued is spread throughout the $20^{\text {th }}$ century in the British Isles, as elsewhere in its range, possibly benefiting from reduced exploitation and increased protection and in the British Isles may have peaked in 2000 (JNCC 2014a).. Based on the SMP index, the current projections for the period 2000-2013 suggest that between 2000 and 2013 all three species declined, but since there is only one estimate for the whole of the UK we cannot calculate a confidence interval for those changes. The most recent estimates (2013) of number of coastal-breeding birds are lower than they were in 1969-1970 in all three species.The SMP index mostly contains coastal colonies (Eaton et al. 2013) and may not be fully representative of the overall populations that also breed on roofs in built-up areas and in inland colonies (i.e., colonies more than $5 \mathrm{~km}$ from the high water line). This might be particularly true for Herring and Lesser Black-backed gulls that breed in large numbers on roofs and inland (Mitchell et al. 2004) and might explain why their projected absolute numbers by the SMP index for 2000 
appeared slightly lower than the Seabird 2000 census. Most importantly, however, the SMP index accurately reflected the population trends between the Seabird Colony Register and Seabird 2000, therefore their projections of the current population trends are likely true. For all three species the British Isles represent a significant proportion of the world population of these species and thus hosts internationally important numbers (Mitchell et al. 2004). Yet, the Herring Gull has recently been added to the U.K.’s Red List (Eaton et al. 2009). The Lesser Black-backed and Great Black-backed gulls are on the Amber List. Other North Atlantic population of large gulls showed similar temporal changes in abundance (Bond et al. this volume; Mittelhauser et al. this volume; Regular et al. this volume; Wilhelm et al. this volume).

In addition to differences between species, we also found regional differences in GR for at least the Herring Gull and the Great Black-backed gulls. Between 1969 and 2002 Herring Gulls declined in the west and the north with the possible exception of the Irish sea where the population decline was not significant, and no significant changes in the east and the south. Although the regional differences in GR of Great Black-backed Gulls was marginally significant, it is clear that populations along the British North Sea increased whereas the numbers tended to decrease, although not statistically significant, along the Atlantic coast. In contrast most regions exhibited significantly increasing numbers of Lesser Black-backed Gulls between 1969-2002, but there was also a significant decline in the Minches and Western Scotland (see also Thom 1986). Regional variation in population changes in Herring and Great Black-backed gulls is further supported by recent avian atlas work that also showed that their distribution within Britain has changed (Balmer et al. 2013). Herring and Great Black-backed gulls used to be concentrated along the western seaboard and along the northern coast of the British Isles where the largest declines occurred. Both species used to be much rarer on the eastern seaboard along the North Sea coast and the 
southern coast of England where some colonies are now expanding and new colonies are forming in previously unoccupied areas. Thus some areas which were previously by a low proportion of the British population may now contain significant numbers of the British population (e.g., Grant et al. 2013).

Furthermore there were also distinct shifts in the habitat occupied by Herring and Lesser Black-backed gulls (Mitchell et al. 2004, Balmer et al. 2013). Both Herring and Lesser Black-backed gulls now nest in larger numbers on artificial structures (Mitchell et al. 2004; Rock 2005). Lesser Black-backed Gulls can also nest inland in substantial numbers (22\% of the total population in Seabird 2000) whereas less than 2\% of Herring and Great Black-backed gulls breed inland (Mitchell et al. 2004). However, inland colonies have only been systematically surveyed for the Seabird 2000. Inland colonies of Lesser Black-backed Gulls may have been under-represented in Operation Seafarer and Seabird Colony Register and if so, those counts are possibly too low, and the estimated population increase of Lesser Black-backed Gulls between 1969 and 2002 has possibly been over-estimated. Interestingly, we found relationships between changes in numbers of coastal- and roof-nesting numbers of Herring and Lesser Black-backed gulls when considering RSRs. The more coastal-nesting Herring Gulls lost in a RSR between 1970 and 2000, the larger the number of roof-nesting Herring Gulls in that same RSR in 2000. This could mean that artificial structures now act as refuges, with urban sites possibly offering more food and safer nesting sites from predators (Monaghan and Coulson 1977; Raven and Coulson 1997). However, the increases in roofnesting Herring Gulls are by far not sufficient to make up for losses in coastal-nesting Herring Gulls. Counting gulls in urban areas is tricky, and it has been suggested that the available estimates seriously underestimate the true number of urban nesting gulls (Rock 2005; Calladine et al. 2006). In contrast, over the same period coastal-nesting Lesser Blackbacked Gulls expanded and they have expanded their populations into both coastal- and roof- 
nesting sites as shown by the positive relationship between changes in coastal- and roofnesting pairs in that species, maybe for the same reasons that Herring Gulls take refuge nesting on roofs in built-up areas.

What are the possible causes for the changes in population size in Herring, Great Black-backed and Lesser Black-backed gulls? Populations maybe constraint by environmental conditions that affect the birds directly or indirectly through bottom-up control the availability of their resources (i.e., from prey to predator), or populations may be selfregulated through local prey depletion (density-dependence) . We found little evidence for density dependence, and only for the Herring Gull. For Herring Gulls, RSR with the highest abundance showed the strongest declines, and this was still true when statistically accounting for spatial variation in abundance (i.e., the decline was not only strong in its former strongholds). Density-dependence in GR has also been shown in British colonies of Blacklegged Kittiwakes (Rissa tridactyla) (Coulson 1983, but see Frederiksen et al. 2005 for more recent analyses)and Northern Gannets (Morus bassanus) (Moss et al. 2002). The densitydependence was reflected in increased foraging ranges around larger Northern Gannets colonies (Lewis et al. 2001) and more depleted fish shoals around larger Black-legged Kittiwake colonies (Ainley et al. 2003). The reason why Herring Gulls showed negative density-dependence, but not Lesser Black-backed and Great Black-backed gulls, is unclear, but this could point to differences in spatial variation in resource utilization between the three species or differences in behavioral processes responding to conspecifics (Frederiksen et al. 2005). Negative density-dependence, however, could also be due to larger groups being more susceptible to other factors, for example being more vulnerable to conspecific nest predation or more likely to contract a parasite or disease.

Competition between gull species has been hypothesized to have led to the decline of Herring Gulls. The analyses of local GR and absolute counts at the local scale of 
administrative areas did not support this hypothesis. Interestingly, between the Seabird Colony Register and Seabird 2000, increases in Lesser Black-backed Gulls were slowed down by high Herring Gull numbers. The effect of high Herring Gull density on reducing Lesser Black-backed Gull population growth could be due to exacerbated competition for resources within and between species.

The results also partly support the spatial variation hypothesis that population trends may be related to environmental factors that vary across the British Isles. The differences between species and RSR in GR suggest that there is unlikely one cause of the declines in the large gulls. There may be a whole range of possible factors related to population trends of these gulls. Food supply is one of the most important factors determining changes in all animal populations (Sinclair and Krebs 2002). There might be regional variation in changes of food resources. Fisheries discards and landfill sites that possibly fuelled the population increase up to the 1970s have declined (Furness and Monaghan 1987; Oro et al. 2004; Votier et al. 2004). This may have been made up for, at least locally, by an alternative food resource, namely swimming crabs of the subfamily Polybiinae (Luczak et al. 2012) and changes in agricultural operations (Coulson and Coulson 2008). Differences in foraging ecology between Herring, Lesser Black-backed and Great Black-backed gulls may also explain differences in populatrion trends, if different components of the marine ecosystem were differentially affected by environmental change. Moreover, the three species also depend on different non-breeding areas with the Lesser Black-backed Gulls migrate south while Herring and Great Black-backed gulls depend on British watrers in the winter. The more recent decline in the Lesser Black-backed Gull may coincide with them becoming less migratory (Banks et al. 2009) or due to environmental changes on their wintering grounds. However, this does not explain the difference in the rate of decline between Herring and Great Blackbacked gulls. 
There are several factors that can directly affect vital rates (survival and productivity0

427 which may vary spatially and between species, therfore potentially explaining differential population trends. We showed that across the U.K. productivity of Herring and Great Blackbacked gulls declined through the 1990s and 2000s, whereas during the same period productivity of the Lesser Black-backed Gull did not change. Temporal trends in adult survival are only available for one site, the large population breeding on Skomer, in southwestern Wales where between 1994 and 2003 survival rates of Herring and Lesser Black-backed gulls declined and coincided with a rapid decline in their numbers breeding at that site (Joint Nature Conservation Committee 2014c). We know very little about spatial variation in survival and productivity of larger gulls. Vital rates can be affected by culling, disease and predation. In the 1970s and 1980s, gulls were culled for conservation and public health reasons that could have contributed to population declines (Mitchell et al. 2004), and some culling is still ongoing but at a reduced rate. Some diseases have been proposed to be important factors in local population declines like avian botulism possibly being the main cause for the large losses of Herring Gulls at some of the Irish colonies (Mitchell et al. 2004) and thiamine deficiency syndrome, proposed being responsible for the declines of Herring Gulls in the Baltic Sea (Balk et al. 2009). Predation, particularly by non-native predators, may also have contributed to population declines. For example American mink (Mustela vison) may have been responsible for widespread breeding failures and colony abandonment in gulls in West Scotland, and removal of American mink has positively affected breeding productivity and colony size in Herring Gulls (Craik 1998). How factors that affect fecundity and survival of gulls interact in driving their population dynamics are poorly understood (Camphuysen and Gronert 2012), and future work needs to focus on these factors for a better understanding of the drivers of populations of large gulls in the British Isles. These potential large declines in a hitherto abundant species have taken many people by surprise and now 
451 clearly mark this species as one of high conservation concern, while it was formerly treated 452 as a pest species. This creates a dilemma for conservation bodies used to assigning gulls a 453 low priority in comparison to other species with which they interact. Differential changes in 454 population abundance between species RSR and nesting habitat point to changes in the gulls' 455 traditional habitats, but the exact drivers of these changes are far from clear. To better 456 understand these changes, we will need good information on what ecological factors affect 457 fecundity and survival in gulls, which are currently poorly explored, and future research needs to pay particular attention to these topics. We urgently need to better understand why the observed population changes have occurred and what this tells us about changes in coastal ecosystems in which the gulls live. The regional variation in population dynamics observed here will necessitate area-specific management strategies rather than one national conservation strategy. We also need to revise existing conservation policies to ensure that the right balance is struck between conservation of the large gulls and management of the environmental problems with which they can be associated.

\section{ACKNOWLEDGMENTS}

We would like to acknowledge the huge effort of many volunteers over the last 4 decades in collating the data on changing gull numbers in the British Isles. We thank two anonymous reviewers for their helpful suggestions that improved the presentation of this manuscript. This work was in part supported by funding from the European Union’s INTERREG IVA Programme (project 2859 ‘IBIS’) managed by the Special EU Programmes 472 Body. 
475 Ainley, D. G., R. G. Ford, E. D. Brown, R. M. Suryan and D. B. Irons. 2003. Prey resources, competition, and geographic structure of Kittiwake colonies in Prince William Sound. Ecology 84: 709-723.

Bairlein, F. 2003. Large-scale networks in bird research in Europe: pitfalls and prospects. Avian Science 3: 49-63.

Balk, L., P.-A. Hägerroth, G. Åkerman, M. Hanson, U. Tjärnlund, T. Hansson, G. T. Hallgrimsson, Y. Zebühr, D. Broman, T. Mörner and H. Sundberg 2009. Wild birds of declining European species are dying from a thiamine deficiency syndrome. Proceedings of the National Academy of Sciences of the USA 106: 12001-12006.

Banks, A. N., N. H. K. Burton, J. R. Calladine and G. E. Austin. 2009. Indexing winter gull numbers in Great Britain using data from the 1953 to 2004 Winter Gull Roost Surveys. Bird Study 56: 103-119.

Balmer, D., S. Gillings, B. Caffrey, B. Swann, I. Downie and R. Fuller. 2013. Bird atlas 2007-11: the breeding and wintering birds of Britain and Ireland. British Trust for Ornithology, Thetford, England, U.K.

Birt, V. L., T. P. Birt, D. Goulet, D. K. Cairns and W. A. Montevecchi. 1987. Ashmole’s halo: direct evidence for prey depletion by a seabird. Marine Ecology Progress Series 40: 205-208.

Bond, A. L., S. I. Wilhelm, G. J. Robertson and S. Avery-Gomm. This volume. Differential declines among nesting habitats of breeding Herring Gulls (Larus argentatus) and Great Black-backed Gulls (Larus marinus) in Witless Bay, Newfoundland and Labrador, Canada. Waterbirds (Special Publication 1).

Calladine, J. R., K. J. Park, K. Thompson and C. V. Wernham. 2006. Review of urban gulls and their management in Scotland. Scottish Executive, Edinburgh, Scotland, U.K. 
499 Camphuysen, C. J. and A. Gronert. 2012. Apparent survival and fecundity of sympatric 500 Lesser Black-backed Gulls and Herring Gulls with contrasting population trends. $501 \quad$ Ardea 100: 113-122.

502 Chabrzyk, G. and J. C. Coulson. 1976. Survival and recruitment in the Herring Gull Larus 503 argentatus. Journal of Animal Ecology 45: 187-203.

504 Coulson, J. C. 1983. The changing status of the Kittiwake Rissa tridactyla in the British Isles, 505 1969-1979. Bird Study 30: 9-16.

506 Coulson, J. C. this volume. Re-evaluation of the role of landfill and culling in the historic changes in the Herring Gull (Larus argentatus) population in Britain. Waterbirds (Special Publication 1).

509

510

511

512

Craik, J. C. A. 1998. Recent mink-related declines of gulls in west Scotland and the beneficial effects of mink control. Argyll Bird Report 14: 98-110.

Cramp, S., W. R. P. Bourne and D. Saunders. 1974. The seabirds of Britain and Ireland. Collins, London, England, U.K.

Davoren, G. K. and W. A. Montevecchi. 2003. Signals from seabirds indicate changing biology of capelin stocks. Marine Ecology Progress Series 258: 253-261.

Dhondt, A. A. 2001. Tradeoffs between reproduction and survival in tits. Ardea 89 (Special Issue): $155-166$.

Dinter, W. P. 2001. Biogeography of the OSPAR Maritime Area: a synopsis and synthesis of biogeographical distribution patterns described for the North East Atlantic. German Federal Agency for Nature Conservation (Bundesamt für Naturschutz), Bonn, Germany. 
Eaton, M. A., A. F. Brown, D. G. Noble, A. J. Musgrove, R. Hearn, N. J. Aebischer, D. W. Gibbons, A. Evans and R. D. Gregory. 2009. Birds of conservation concern 3: the population status of birds in the United Kingdom, Channel Islands and the Isle of Man. British Birds 102: 296-341.

Eaton, M. A., D. E. Balmer, J. Bright, R. Cuthbert, P. V. Grice, C. Hall, D. B. Hayhow, R. D. Hearn, C. A. Holt, A. Knipe and others. 2013. The State of the UK’s Birds 2013. Royal Society for the Protection of Birds, British Trust for Ornithology, Wildfowl and Wetlands Trust, Natural Resources Wales, Natural England, Northern Ireland Environment Agency, Scottish Natural Heritage, and Joint Nature Conservation Committee, Sandy, Bedfordshire, England, U.K.

Frederiksen, M., P. J. Wright, M. P. Harris, R. A. Mavor, M. Heubeck and S. Wanless. 2005. Regional patterns of kittiwake Rissa tridactyla breeding success are related to variability in sandeel recruitment. Marine Ecology Progress Series 300: 201-211.

Friend, M. and J. C. Franson. 1999. Field manual of wildlife diseases - general field procedures and diseases of birds. U.S. Department of the Interior, Geological Survey, Biological Resource Division, National Wildlife Health Center, Madison, Wisconsin.

Furness, R. W. and T. R. Birkhead. 1984. Seabird colony distributions suggest competition for food supplies during the breeding season. Nature 311: 655-656.

Furness, R. W. and P. Monaghan. 1987. Seabird ecology. Blackie and Son Limited, Glasgow, Scotland, U.K.

Furness, R. W., K. Ensor and A. V. Hudson. 1992. The use of fishery waste by gull populations around the British Isles. Ardea 80: 105-113.

Grant, D., D. Robertson, R. Nager and D. McCracken. 2013. The status of breeding gulls on Lady Isle, Ayrshire, 2012. Scottish Birds 33: 298-307. 
548 Guillaumet, A., B. S. Dorr, G. Wand and T. J. Doyle. 2014. The cumulative effects of

549

550

551

552

553

554

555

556

557

558

559

560

561

562

563

564

565

566

567

568

569

570

571

572 management on the population dynamics of the Double-crested Cormorant Phalacrocorax auritus in the Great Lakes. Ibis 156: 141-152.

Hannon, C., S. D. Berrow and S. F. Newton. 1997. The status and distribution of breeding Sandwich Sterna sandvicensis, Roseate S. dougallii, Common S. hirundo, Arctic S. paradisaea and Little Tern S. albifrons in Ireland in 1995. Irish Birds 6: 1-22.

Holloway, S. 1996. The historical atlas of breeding birds in Britain and Ireland 1875-1900. T \& AD Poyser, London, England, U.K.

IBM Corp. 2013. IBM SPSS Statistics for Windows, Version 22.0. IBM Corp, Armonk, N.Y., U.S.A.

Joint Nature Conservation Committee (JNCC). 2014a. Seabird population trends and causes of change: 1986-2013 report. JNCC, Peterborough, England, U.K. http://www.jncc.defra.gov.uk/page-3201, accessed 1 September 2014.

Joint Nature Conservation Committee (JNCC). 2014b. UK regional seas. JNCC, Peterborough, England, U.K. http://jncc.defra.gov.uk/page-1612, accessed 1 September 2014.

Joint Nature Conservation Committee (JNCC). 2014c. Lesser Black-backed Gull Larus fuscus. JNCC, Peterborough, England, U.K. http://jncc.defra.gov.uk/page2886, accessed 1 September 2014.

Kim, S. Y. and P. Monaghan. 2006. Interspecific differences in foraging preferences, breeding performance and demography in herring (Larus argentatus) and lesser black-backed gulls (Larus fuscus) at a mixed colony. Journal of Zoology 270: 664671.

Lewis, S., T. N. Sherratt, K. C. Hamer and S. Wanless. 2001. Evidence of intra-specific competition for food in a pelagic seabird. Nature 412: 816-819. 
573 Lloyd, C. S., M. L. Rasker and K. Partridge. 1991. The status of seabirds in Britain and 574 Ireland. T \& AD, Poyser, London, England, U.K.

575 Luczak, C., G. Beaugrand, J. A. Lindley, J. M. Dewarumez, P. J. Dubois and R. R. Kirby. 2012. North Sea ecosystem change from swimming crabs to seagulls. Biology Letters 8: 821-824.

Mitchell, P. I., S. F. Newton, N. Ratcliffe and T. E. Dunn. 2004. Seabird populations of Britain and Ireland. T \& AD Poyser, London, England, U.K.

Mittelhauser, G. H., R. B. Allen, J. Chalfant, R. P. Schauffler and L. J. Welch. This volume. Trends in the nesting populations of Great Black-backed Gull (Larus marinus) and Herring Gull (Larus argentatus) in Maine, USA, 1977-2013. Waterbirds (Special Publication 1).

Monaghan, P. and J. C. Coulson. 1977. The status of large gulls nesting on buildings. Bird Study 24: 89-104.

Montevecchi, W. A. 1993. Birds as indicators of change in marine prey stocks. Pages 217266 in Birds as Monitors of Environmental Change (R. W. Furness and J. J. D. Greenwood, Eds.). Chapman \& Hall, London, England, U.K.

Moss, R., S. Wanless and M. P. Harris. 2002. How small Northern Gannet colonies grow faster than big ones. Waterbirds 25: 442-448.

Newton, I. 2013. Bird populations. HarperCollins Publishers, London, England, U.K.

Noordhuis, R. and A. L. Spaans. 1992. Interspecific competition for food between Herring Larus argentatus and Lesser Black-backed Gull L. fuscus in the Dutch Wadden Sea area. Ardea 80: 115-132.

Oro, D., E. Cam, R. Pradel and A. Martínez-Abrain. 2004. Influence of food availability on demography and local population dynamics in a long-lived seabird. Proceedings of the Royal Society of London B 271: 387-396. 
598

599

600

601

602

603

604

605

606

607

608

609

610

611

612

613

614

615

616

617

618

619

620

621

OSPAR Commission. 2014. The North East Atlantic. OSPAR Commission, London, England, U.K. http://www.ospar.org/content/regions.asp?menu=00020200000000_000000_000000, accessed 1 September 2014.

Raven, S. J. and Coulson, J. C. 1997. The distribution and abundance of Larus gulls nesting on buildings in Britain and Ireland. Bird Study 44: 13-34.

Regular, P. M., S. I. Wilhelm, C. Gjerdrum, A. W. Boyne and G. J. Robertson. This volume. Contrasting trends of Herring Gulls (Larus argentatus) and Great Black-backed Gulls (Larus marinus) along the Bay of Fundy and Atlantic coasts of Nova Scotia and New Brunswick, Canada. Waterbirds (Special Publication 1).

Rock, P. 2005. Urban gulls: problems and solutions. British Birds 98: 338-354.

Sinclair, A. R. E. and C. J. Krebs. 2002. Complex numerical responses to top-down and bottom-up processes in vertebrate populations. Philosophical Transactions of the Royal Society of London B, 357: 1221-1231.

Thom, V. 1986. Birds in Scotland. T. \& A.D. Poyser, Calton, England.

Thomas, G. E. 1993. Estimating annual total heron population counts. Applied Statistics 42: 473-486.

Votier, S. C., R. W. Furness, S. Bearhop, J. E. Crane, R. W. G. Caldow, P. Catry, K. Ensor, K. C. Hamer, A. V. Hudson, E. Kalmbach and others. 2004. Changes in fisheries discard rates and seabird communities. Nature 427: 727-730.

Wilhelm, S. I., J.-F. Rail, P. M. Regular, C. Gjerdrum and G. J. Robertson. This volume. Large-scale changes in abundance of breeding Herring Gulls (Larus argentatus) and Great Black-backed Gulls (Larus marinus) relative to reduced fishing activities in southeastern Canada. Waterbirds (Special Publication 1). 
622 Table 1:. Population growth rate (GR) for Herring, Lesser Black-backed and Great

623 Black-backed Gulls separately for each Regional Seas Regions (RSR, 1: Northern North

624 Sea, 2: Southern North Sea, 3: Eastern English Channel, 4: Western English Channel \&

625 Celtic Sea, 4a: westcoast of Republic of Ireland, 6: Irish Sea, 7: Minches \& West

626 Scotland, 8: Scottish Continental Shelf). For each RSR, average GR (lower and upper

$62795 \%$ confidence interval) was calculated over all the administrative units contained in

628 that RSR; where the $95 \%$ confidence interval did not overlap with 0 are shown in bold

629 and represent RSR where abundance increased or decreased.. RSR 2 only had one

630 administrative unit with active Great Black-backed Gull colonies and was therefore

631 excluded from analysis.

\begin{tabular}{|c|c|c|c|}
\hline \multirow[t]{2}{*}{ RSR } & \multicolumn{3}{|c|}{ GR } \\
\hline & Herring Gull & Lesser Black-backed Gull & Great Black-backed Gull \\
\hline 1 & $-0.32(-0.59 ;-0.05)$ & $0.27(-0.14 ; 0.68)$ & $0.42(0.03 ; 0.81)$ \\
\hline 2 & $0.60(-0.11 ; 1.31)$ & $0.99(0.98 ; 1.00)$ & \\
\hline 3 & $0.16(-0.47 ; 0.79)$ & $0.77(0.39 ; 1.15)$ & $0.73(0.39 ; 1.07)$ \\
\hline 4 & $-0.33(-0.72 ; 0.06)$ & $0.47(0.05 ; 0.89)$ & $-0.19(-0.73 ; 0.36)$ \\
\hline $4 a$ & $-0.89(-0.94 ;-0.84)$ & $0.42(0.10 ; 0.74)$ & $-0.31(-0.67 ; 0.05)$ \\
\hline 6 & $-0.21(-0.69 ; 0.27)$ & $0.40(-0.06 ; 0.86)$ & $-0.02(-0.57 ; 0.53)$ \\
\hline 7 & $-0.52(-0.98 ;-0.06)$ & $-0.47(-0.76 ;-0.18)$ & $-0.22(-0.67 ; 0.23)$ \\
\hline 8 & $-0.58(-0.78 ;-0.38)$ & $-0.15(-0.40 ; 0.10)$ & $-0.29(-0.68 ; 0.10)$ \\
\hline
\end{tabular}


633 Table 2. Association between population growth rate (GR) and the total number of 634 apparently occupied nests (AON) at the first census for each of two periods (1970-1985 635 is from Operation Seafarer to Seabird Colony Registry, and 1985-2000 is from Seabird 636 Colony Registry to Seabird 2000) accounting for Regional Seas Regions (RSR) (General 637 Linear Model with RSR as fixed effect). Shown are the estimates of change in GR per 638 10,000 AONs \pm SE. Significant associations are in bold. Patterns were similar across all 639 RSRs (all interactions between RSR and abundance were non-significant).

640

Total Numbers of AON at Start of Interval

\section{GR}

Herring Gull

1970-1985

$-0.303 \pm 0.104$

$-0.146 \pm 0.292$

$-0.382 \pm 0.75$

$$
F_{1,60}=8.57, P=0.005
$$

$F_{1,56}=0.25, P=0.620$

$F_{1,46}=0.12, P=0.734$

1985-2000

$-0.599 \pm 0.232$

$-0.082 \pm 0.294$

$-0.690 \pm 0.75$

$$
F_{1,63}=6.65, P=0.012
$$

$F_{1,58}=0.08, P=0.782$

$F_{1,46}=0.23, P=0.587$

Lesser Black-backed Gull

1970-1985

$-0.071 \pm 0.128$

$-0.319 \pm 0.340$

$-0.577 \pm 0.75$

$$
F_{1,53}=0.30, P=0.584
$$

$F_{1,53}=0.88, P=0.353$

$F_{1,43}=0.17, P=0.686$

1985-2000

$$
-0.458 \pm 0.223
$$

$-0.365 \pm 0.272$

$-0.343 \pm 0.75$

$$
F_{1,55}=4.23, P=0.044
$$

$F_{1,55}=1.81, P=0.184$

$F_{1,43}=0.09, P=0.772$

Great Black-backed Gull

1970-1985

$$
-0.029 \pm 0.120
$$

$0.077 \pm 0.303$

$$
-0.64 \pm 0.75
$$

$$
F_{1,43}=0.06, P=0.812
$$

$$
F_{1,43}=0.07, P=0.800
$$

$F_{1,43}=0.09, P=0.772$

1985-2000

$$
-0.193 \pm 0.266
$$

$0.227 \pm 0.314$

$$
0.318 \pm 0.75
$$

$F_{1,46}=0.53, P=0.471$

$F_{1,46}=0.52, P=0.473$

$F_{1,46}=0.05, P=0.819$ 


\section{FIGURE CAPTIONS}

Figure 1. Changes in coastal-nesting populations of (A) Herring Gull, (B) Lesser Blackbacked Gull and (C) Great Black-backed Gull between 1970 and 2013. The solid line and closed symbols give the observed number of apparently occupied nests (AON) for coastal colonies from Operation Seafarer, Seabird Colony Register and Seabird 2000. The open symbols and dashed line show the changes in roof-nesting gulls (data from Monaghan and Coulson (1977) for 1976, Raven and Coulson (1997) for 1993-1995 and Mitchell et al. (2004) for 1998-2002). The stars and dotted line give the predicted changes in number based on the Seabird Monitoring Programme (SMP) index relative to the Seabird Colony Register Count. Note that SMP data only cover the U.K., whereas the absolute counts cover the British Isles. However, by the mid-1980s the numbers of gulls breeding in the Republic of Ireland were so small (typically $<10 \%$ ) that the differences between U.K. and British Isles numbers were negligible.

Figure 2. Spatial variation in population growth rate (GR) by administrative unit for (A) Herring Gull, (B) Lesser Black-backed Gull and (C) Great Black-backed Gull. The darker the color of the administrative unit on the map, the greater the population decrease, with the lightest colors representing population declines and the darkest colors population increases. Administrative units are grouped into Regional Seas Regions (RSR), which are indicated by the different numbers and lines around the coast. Significant differences in GRs between RSRs are shown in Table 1.

Figure 3. Relationship between number of roof-nesting gulls in Seabird 2000 and the absolute number of apparently occupied nests (AON) of coastal nesting gulls that were 
667 lost (left part of the horizontal axis) or gained (right part of the horizontal axis) between 668 Operation Seafarer and Seabird 2000 for each of the Regional Seas Regions for Herring 669 Gulls (gray symbols) and Lesser Black-backed Gulls (black symbols); insufficient 670 numbers of Great Black-backed Gulls nest on roofs for this analysis. 
672 Figure 1.
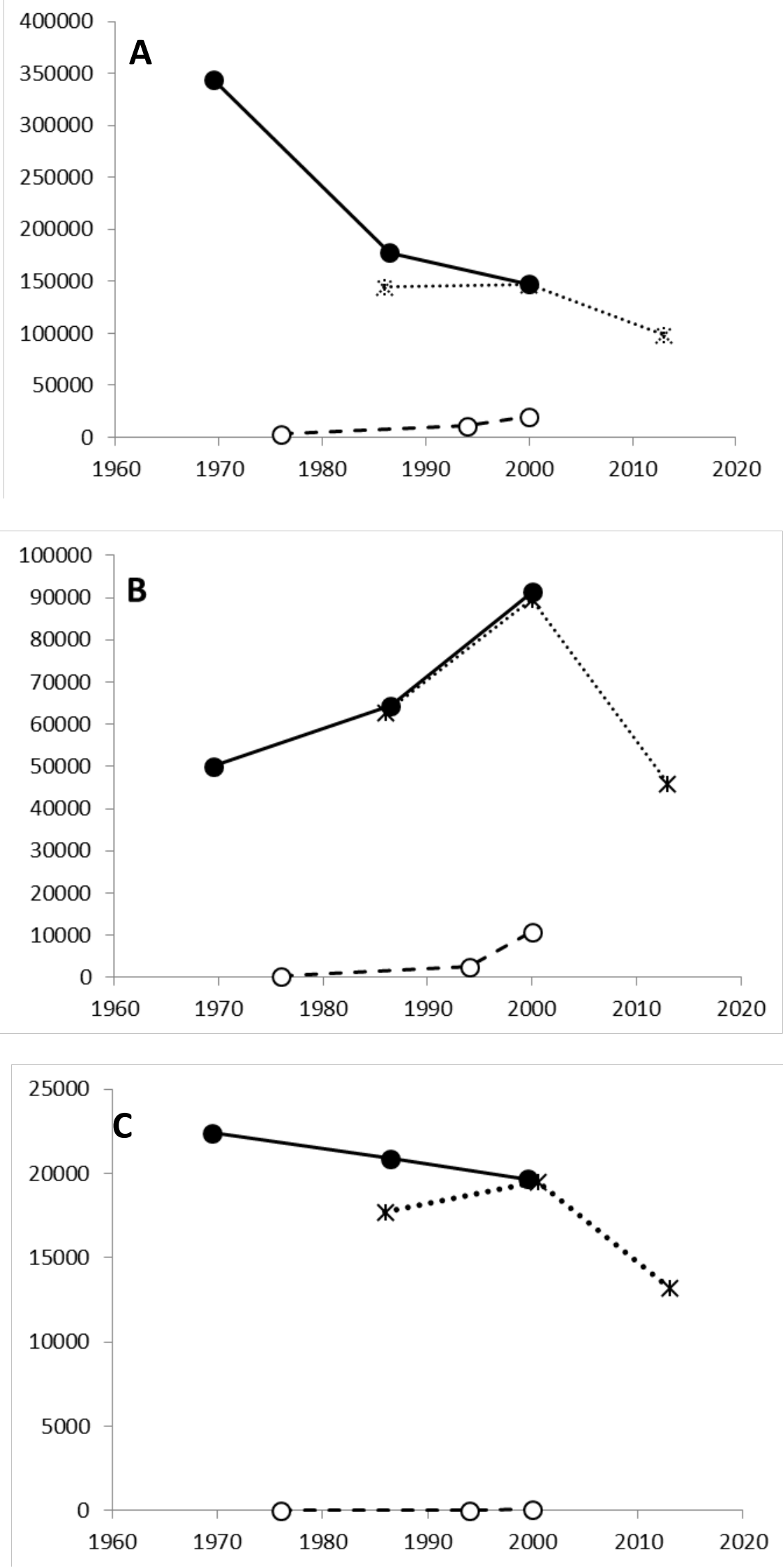
Figure 2a.

\section{Herring Gull}

$-1.00--0.750$

$-0.749--0.500$

$-0.499--0.250$

$-0.249-0.000$

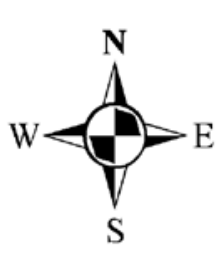

$0.001-0.250$

$0.251-0.500$

$0.501-0.750$

$0.751-1.000$

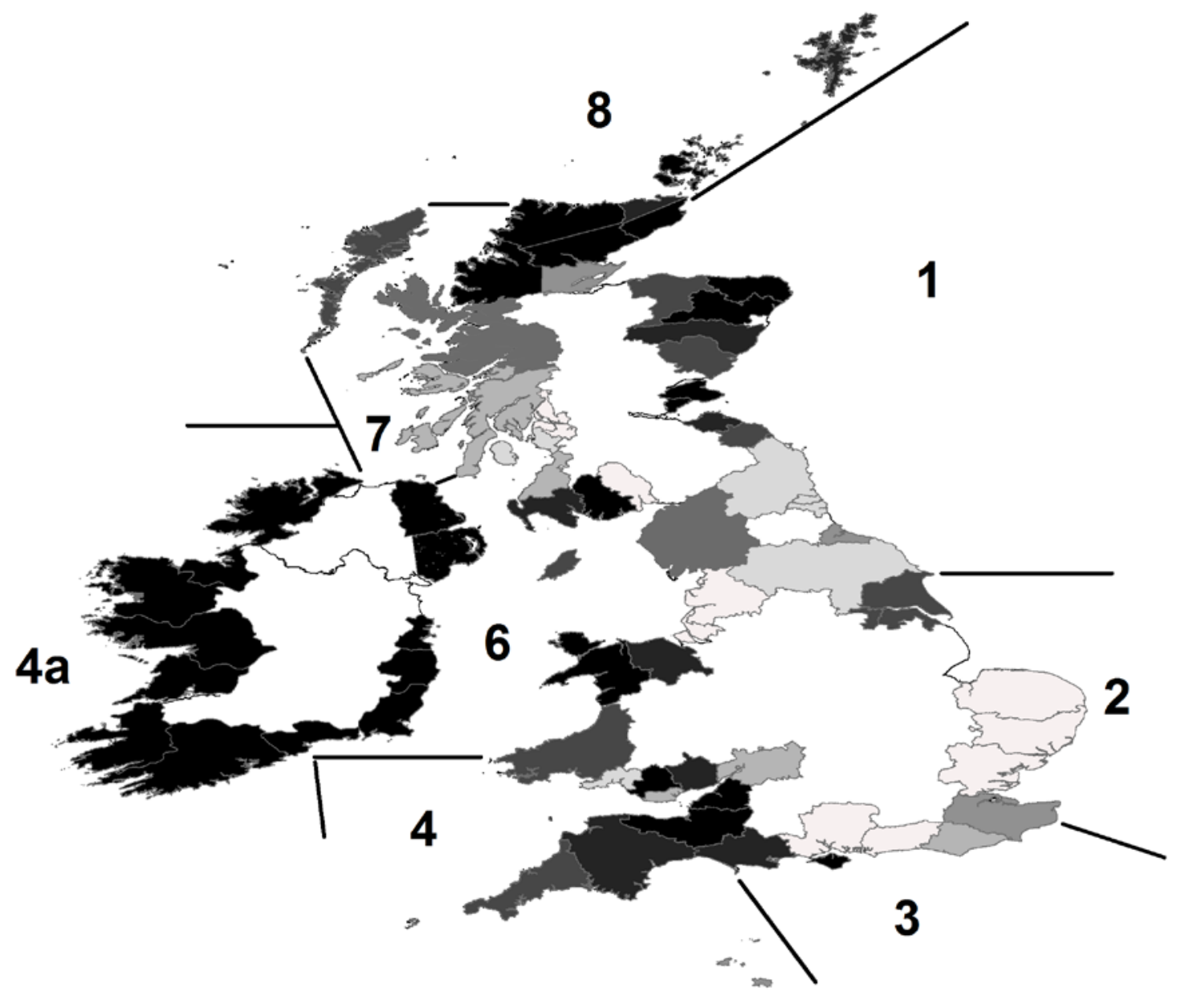


Figure 2b.

\section{Lesser Black-backed Gull}
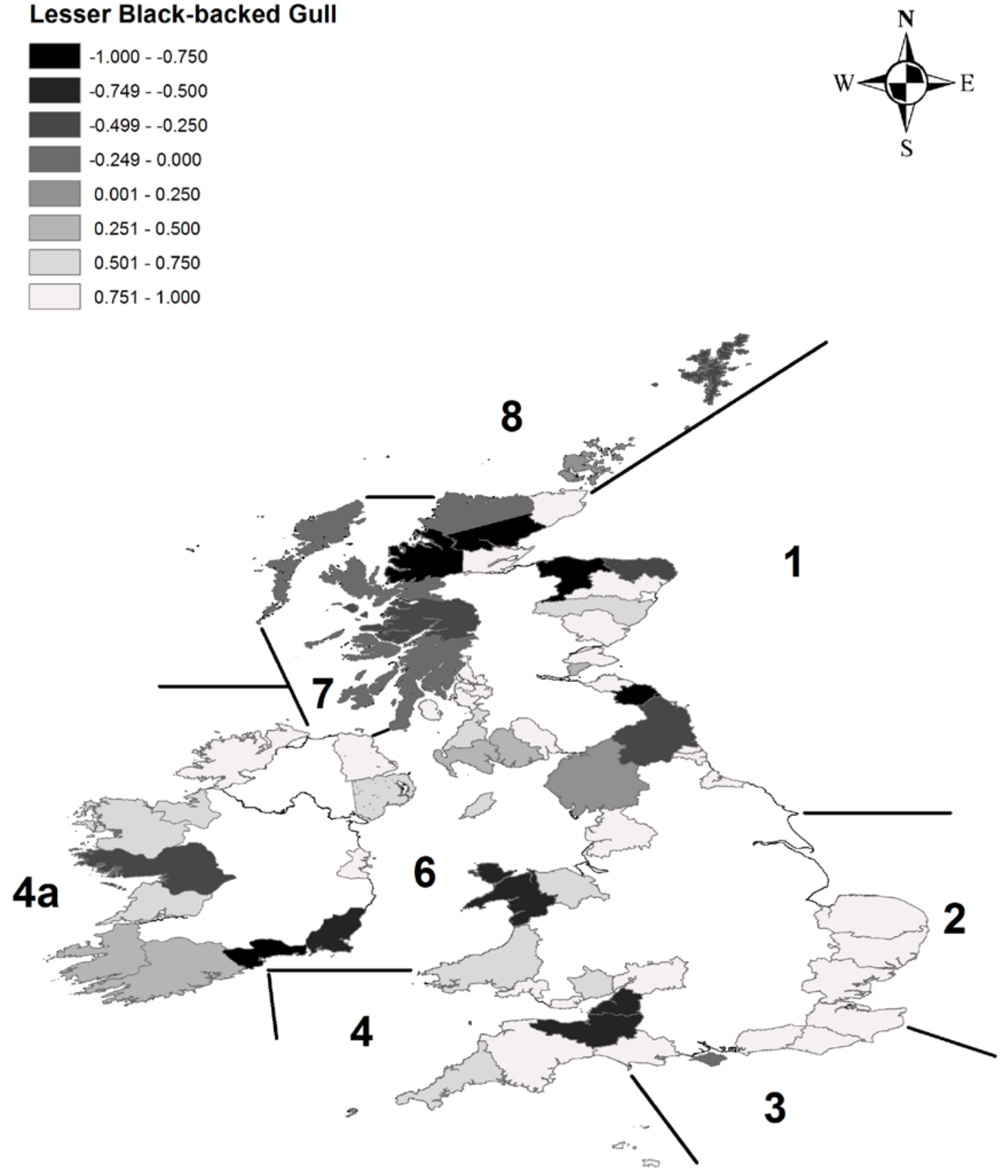
Figure 2c.

\section{Great Black-backed Gull}
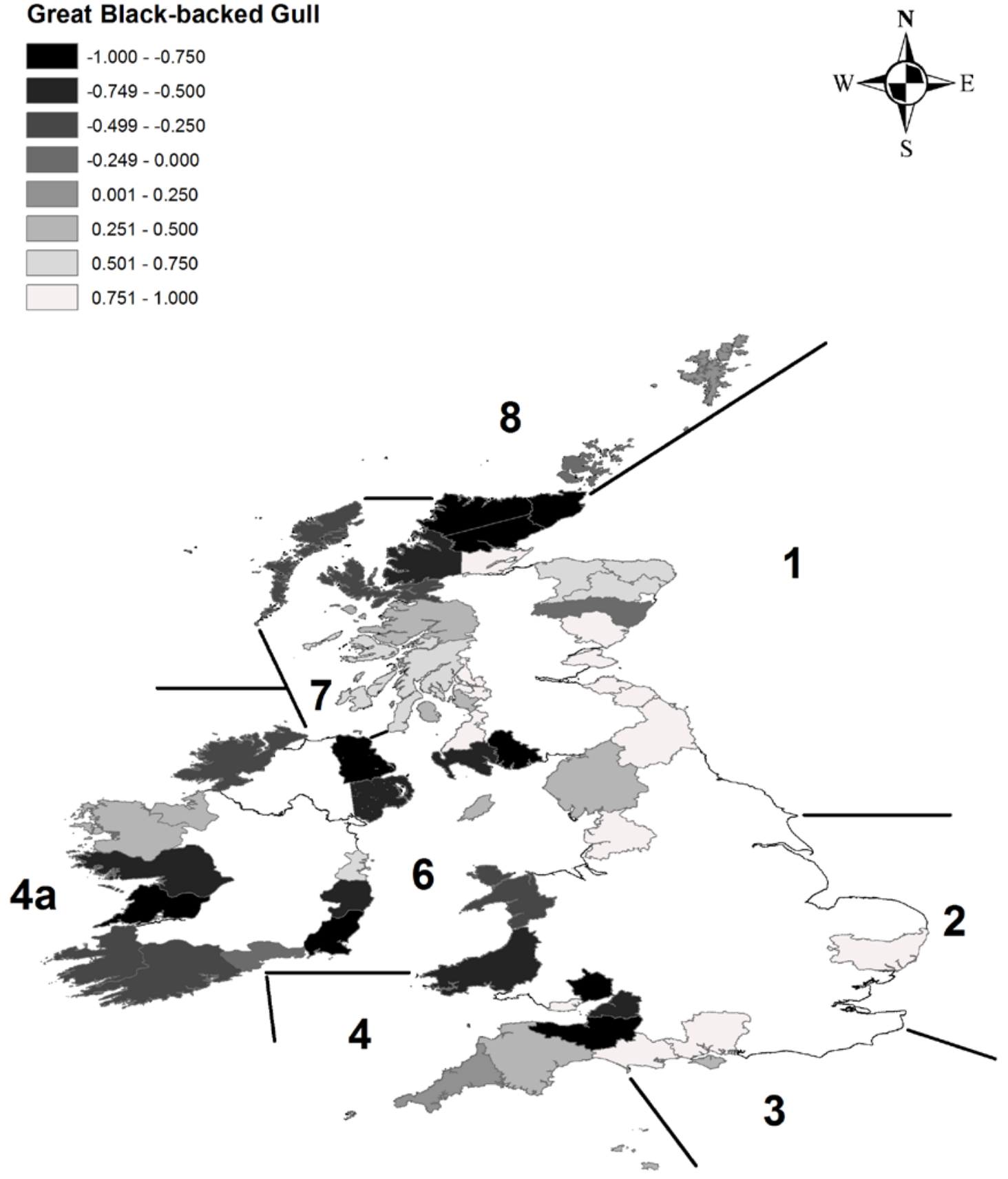
687 Figure 3.

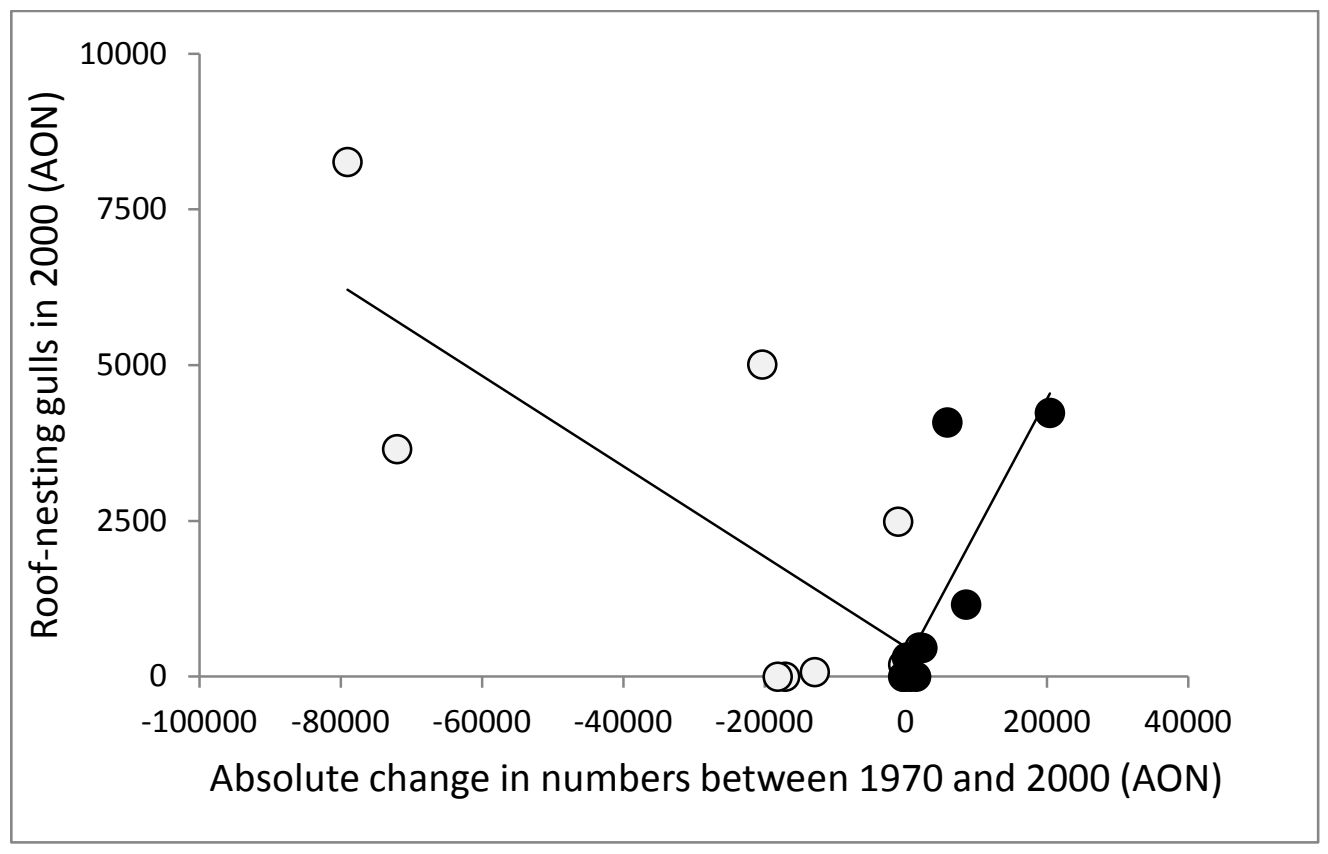

